\title{
Improving Pneumatic Control System of FMS Production Line Based on PID Control Algorithm
}

\author{
Gui Yin Chen \\ (Electric and Electronics School of Wuhan Institute of Shipbuilding Technology, Wuhan 430050, \\ Hubei, China) \\ Email:940173762@qq.com
}

Keywords: PID; PLC; FMS; Production line; Pneumatic control

\begin{abstract}
The paper proposes improving Pneumatic control system of FMS production line based on PID control algorithm. It analyzes the problems produced by air compressor when the control working. Based on PID control function, the use of Siemens S7-200 PLC and the inverter to improve the system structure, especially introduces the adjustment of PID in detail. The practical application shows the air pressure stability for the improved system, it has good application prospect.
\end{abstract}

\section{Intruduction}

Pneumatic industrial in China has formed a complete series models, species diversity, with a certain scale and technical level of the industrial system. Today aerodynamic development is the theme of the World Public pneumatic products accelerate structural adjustment and development of pneumatic technology, change their thinking patterns, adapt to green production, green energy, low carbon safety [1][2][3]. Pneumatic technology not only has its own energy-saving and environmental protection features, but also presented together with other green production technology integration, features low-carbon development [4][5][6]. Hence it needs to speed up the adjustment of product structure, develop more advanced technology, and focus on the use of new materials, new technology, and comprehensive application of multiple technologies. It also will design and complete system of pneumatic products, material use, sealing structure, higher and newer requirements, For FMS pneumatic technology in the production line, this paper proposes improve system efficiency by optimizing the system architecture.

Over the past decade, pneumatic technology is one of the most effective techniques for the production process automation. Pneumatics air as a medium, a convenient source, and no pollution, can work in dusty flammable environments such as, rapid control operation, a significant advantage of low cost, currently in FMS production line, precision machining, constraints, medical, packaging more industrial applications, which greatly improves production efficiency and product quality in manufacturing. According to statistics, in the industrialized countries, the fully automated production line is equipped with a pneumatic system, about 30 percent. Research and application of manufacturing pneumatic and pneumatic technologies in China started late, many places still use the relay contactor control, so there are a lot of shortcomings, such as the control cabinet bulky, complex wiring; mechanical contacts and more reliability is low; some troubleshooting difficulties. Meanwhile, the pneumatic air compressor control system using the traditional open-loop control mode, the disadvantage of this operating mode include: the supply air pressure between the upper and lower volatility cannot guarantee constant supply, affect the performance of FMS production line of pneumatic tools and life; the use of the main air compressor and air compressor spare holiday cannot work effectively, it will reduce the life of the main air compressor. While the main air compressor is running, drag the motor load and did not stop, so that its power consumption is about $30 \%$ of its rating, it serious waste of energy; for this series of questions, based on PLC and PID algorithm frequency control technology to transform its designed production lines PMS constant pressure pneumatic control system, the main air compressor and air compressor rotation backup job, in order to achieve control convenient, safe, reliable, and efficient energy-saving purposes. 


\section{System Structure and Control Scheme}

Original FMS production line control system is an open loop control mode, mainly by electric motors, air compressors, pressure transmitter cabinet, inverter and other components. After analysis, we improve the open-loop control system to closed-loop control, the main load unchanged. Taking a FMS production line for example, the system configuration as shown in Fig. 1, the selection of Ingersoll-Rand HP-100 type screw compressor, motor power $75 \mathrm{~kW}$; the two sets of air compressors and network use, under normal production conditions they are working and backup [2]; PLC choose a Siemens S7-200 series PLC to achieve control by electrical part, including five parts: the start, run, stop, switch, alarm and fault diagnosis; inverter selected Siemens products, the inverter uses MM430 energy-saving module, can greatly reduce the motor frequency noise, reducing pollution on the grid, but also can reduce the compressor motor temperature.

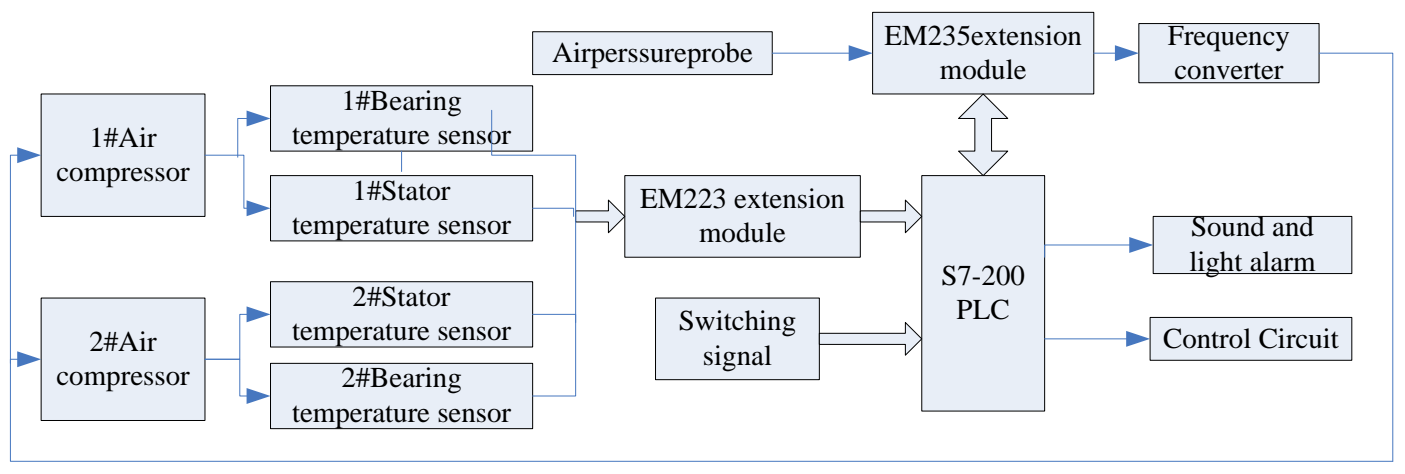

Figure. 1 System Structure

For many problems existing in Original air compressor supply control, in order to meet the FMS production line pneumatic system automatically control requirements, the author introduces the design of constant supply of energy-saving air compressor control system based on frequency control PID, as shown in Fig. 2.

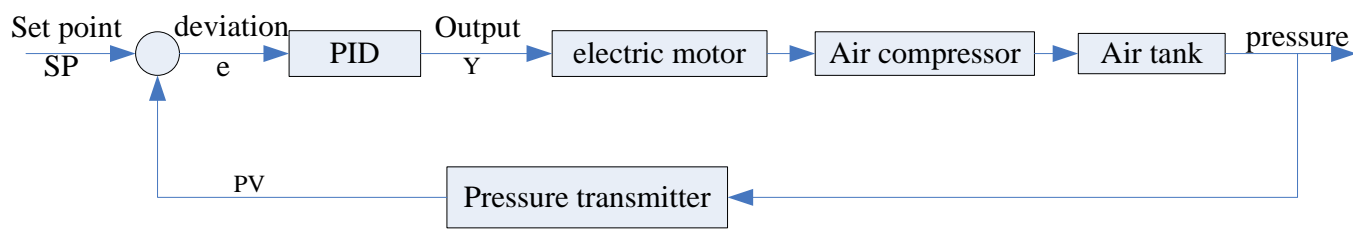

Figure. 2 Closed Loop Control System of Frequency Conversion Air Compressor

The system provides two modes, namely manual and automatic, with on-site real-time control, can display the status and fault alarm functions. When the manual mode, the air compressor is controlled by a dedicated switch, can be directly output air pressure without the pneumatic system output from the effect of pressure. To prevent fatigue running of master compressor, we switched to another wind turbine operation by setting the total running time. 1\# Compressor and 2\# Compressor are switched. Cycles and timing can be arbitrarily set according to need. Alarm signals are audible form. Sound the alarm with the electric flute, directly with the button lift, when troubleshooting, alarm indication will automatically disappear. When the automatic mode, with the gas tank pressure as a control object, detected by a remote air tank pressure sensor to the actual pressure $\mathrm{P}$, the $\mathrm{P}$ with a transmitter is converted into a uniform standard electrical signals sent to the EM235 module A/D conversion within the analog to digital conversion unit, into the inside of PLC, PLC compared the detected real time air pressure $\mathrm{P}$ and the pressure set value $\mathrm{P} 0$, calculates according to PID control mode has been set by the size of the difference e, generates control signals sent directly to the inverter, the motor is controlled by the inverter operating frequency and speed, so as to achieve the actual pressure $\mathrm{P}$ is always close to the set pressure $\mathrm{P} 0$ precise control purposes. At the same time, the frequency control is also an extra-frequency and frequency switching to improve efficiency. In 
addition, the control system uses the drive motor to start the air compressor to avoid the impact of current and the air compressor starts to bring the mechanical shock.

\section{PID Algorithm}

PID is proportional-integral-derivative control algorithm in closed-loop control system. In analog regulator, PID control algorithm for the simulation expression [7] [8] is:

$$
\mathrm{Y}(t)=K_{c} e(t)+K_{c} \frac{1}{T_{I}} \int_{0}^{t} e(t) d t+M_{\text {initial }}+K_{c} T_{D} \frac{d e(t)}{d t}
$$

Where: $\mathrm{Y}(\mathrm{t})$ is the output of the loop control algorithm; $\mathrm{KC}$ is the loop gain; TI is the integral time constant; TD is the derivative time constant; $\mathrm{e}(\mathrm{t})$ is the error; Minitial is the initial value of loop control algorithm output.

Formula (2) obtained after processing discrete PID algorithm expression:

$$
Y_{n}=K_{C} e_{n}+\frac{K_{C} T}{T_{I}} \sum_{i=1}^{n}\left(e_{i}\right)+\frac{K_{C} T_{D}}{T}\left(e_{n}-e_{n-1}\right)
$$

Where, Yn is loop control output value which is calculated on sampling time $\mathrm{n}$; en is the deviation of the sampling time $\mathrm{n}$; en- 1 is the last deviation; ei is the $\mathrm{i}$-th sample deviation; $\mathrm{T}$ is the sampling time; Yinitial is the initial value of the integral.

PLC utilizing repetitive processing, Formula 2 can be simplified to Formula 3:

$$
\begin{aligned}
& Y_{n}=K_{C} e_{n}+\frac{K_{C} T}{T_{I}} e_{n}+Y X+\frac{K_{C} T_{D}}{T}\left(e_{n}-e_{n-1}\right) \\
& =K_{C}\left(S P_{n}-P V_{\mathrm{n}}\right)+K_{C} \frac{T}{T_{I}}\left(S P_{n}-P V_{n}\right)+Y X+K_{C} \frac{T_{D}}{T}\left[\left(S P_{n}-P V_{n}\right)-\left(S P_{\mathrm{n}-1}-P V_{\mathrm{n}-1}\right)\right] \\
& =K_{C}\left(S P_{\mathrm{n}}-P V_{\mathrm{n}}\right)+K_{C} \frac{T}{T_{I}}\left(S P_{n}-P V_{n}\right)+Y X+K_{C} \frac{T_{D}}{T}\left(P V_{n-1}-P V_{\mathrm{n}}\right)
\end{aligned}
$$

Where, $\mathrm{SPn}$ is a given value of the sampling time $\mathrm{n}$; PVn is the process variable value at sample time $n$; PVn-1 is the sampling time $n-1$ of process variable values; YX is the sampling time $n-1$ and the integral, which is all sampling time sum of the integral term. Calculated once every integral term, YX is updated once its initial value is typically adjusted as Yinitial.

PID operation of the integral action can eliminate the static error of the system, improve accuracy, enhance the ability to adapt to changes in system parameters; and derivative action can overcome inertia lag, improve system stability and anti-jamming capability, can improve the system dynamic response speed. Therefore, PID controls pressure slow process with good results [5].

\section{PLC External I/O Connection}

According to the system requirements, select the Siemens PLC S7-200 CPU224 as the control center, I/O points of CPU224 is 14/10, extended an EM 235 analog input module, which is A/D converter module, with four analog inputs and one analog output, 12-bit $\mathrm{A} / \mathrm{D}$, the input signal is in turn collected by the multiplexer, the value used is the value of the digital filter to strike a sampling rate of the average of the output signal of the pressure sensor, after the transmitter conditioning and amplification process, changed to standard signal of $0 \sim 5 \mathrm{~V}$, EM 235 module automatically complete A/D conversion; while expanding a digital input/output module EM223, which has four inputs and four outputs, this system uses two outputs, namely Q2.0 and Q2.1, so fully meet the requirements of the system.

The design of FMS production line pneumatic control system mainly involves eight digital inputs and one analog input, 10 digital outputs, set the I/O points are shown in Table 1. Set six operating 
keys, two switch sensors and an analog sensor as input signals. This six operating keys are automatic mode switch, manual mode switch, stop button, mute button and two under manual control button switch control fan operation, two sensors to reflect the drag of the air compressor motor stall fault heat relay switch, which expanded an analog input module EM235 is mainly used to measure the pressure value, in addition to the expansion of an EM223 digital input/output modules to provide more input/output points [7][8].

Table 1 I /O Address Allocation of PLC

\begin{tabular}{|c|c|c|c|c|c|}
\hline \multicolumn{3}{|c|}{ Input } & \multicolumn{3}{|c|}{ Output } \\
\hline No. & Name & Address & No. & Name & Address \\
\hline 1 & Compressor start & $\mathrm{I} 0.0$ & 1 & Fault Display & Q0.0 \\
\hline 2 & Compressor stop & I0.1 & 2 & $\begin{array}{l}\text { Middle/High pressure } \\
\text { display }\end{array}$ & Q0.1 \\
\hline 3 & $\begin{array}{l}\text { Automatic/manual } \\
\text { conversion }\end{array}$ & $\mathrm{I} 0.2$ & 3 & Low pressure display & Q0.2 \\
\hline 4 & Alarm Clear & $\mathrm{I} 0.3$ & 4 & Alarm & Q0.3 \\
\hline 5 & \#1 fan control & $\mathrm{I} 0.4$ & 5 & Relay KM1 & Q0.4 \\
\hline 6 & \#1 fan control state & I1.0 & 6 & Relay KM2 & Q0.5 \\
\hline 7 & \#1 fan motor status & I1.1 & 7 & $\begin{array}{l}\text { \#1 fan motor running } \\
\text { display }\end{array}$ & Q1.0 \\
\hline 8 & \#2 fan control state & I1.2 & 8 & $\begin{array}{l}\text { \#2 fan motor running } \\
\text { display }\end{array}$ & Q1.1 \\
\hline \multirow[t]{3}{*}{9} & Pressure signal & AIW0 & 9 & Manual status display & $\mathrm{Q} 2.0$ \\
\hline & & & 10 & $\begin{array}{ll}\text { Automatic } & \text { status } \\
\text { display }\end{array}$ & Q2.1 \\
\hline & & & 11 & $\begin{array}{ll}\text { Pressure } & \text { Analog } \\
\text { Output } & \end{array}$ & AQW0 \\
\hline
\end{tabular}

\section{Control System Software Design}

The software architecture flowchart of the control system is shown in Fig. 3.

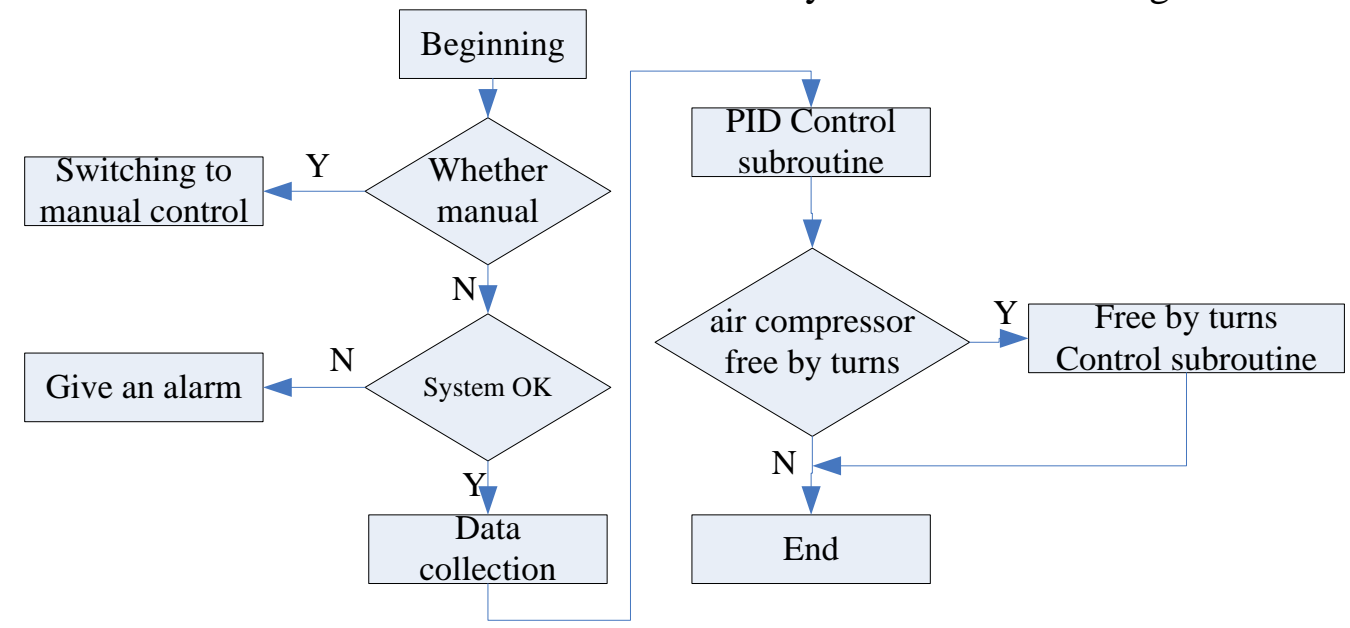

Figure. 3 The software architecture flowchart of the control system

Software design of the control system is mainly the PID programming of PLC. Measured pressure value by the conversion of the pressure transmitter, the expansion module EM235 analog to digital conversion into the internal PLC, PLC will be detected in real time pressure P and the pressure set point P0 compare the results of the comparison by the built-in PID controller PLC calculates a control signal that is used to control the output frequency, the frequency control air compressor motor, so that the gas pressure of the air compressor to maintain a given pressure in the vicinity. To the pressure given by the pressure value and the measured value of the constant comparison of the feedback obtained deviation e. The deviation and then by a built-in PID controller calculates the output signal, the analog to digital expansion module EM235 digital to 
analog conversion, input to the inverter. Induction motor speed control inverter output frequency of the alternating current value and the corresponding output $\mathrm{AC}$ frequency control of induction motor speed, until the same line pressure and the set pressure. Such pressure was relatively constant and relatively small fluctuations.

\section{PID Adjustment}

S7-200 can be used to PID control. It can directly use PID instructions which are provided by S7-200 PLC, it can also uses PID instruction wizard which are provided by STEP7-Micro/WIN. Either way, can support up to eight PID control loops, this system has only one loop, using a PID instruction wizard. Through this wizard, can help users easily generate a closed-loop control process PID algorithm. Users simply call the PID wizard generates subroutines in the main program, the wizard can perform most PID automatic programming operation, PID control tasks can be completed. Process is as follows:

Set PID parameters in wizard [9][10]:

a. Define the loop SP (a given value) range: minimum (Low Range) is 0, the upper limit (High Range) is 100, indicating that the percentage of a given value in the range of accounting process feedback range. In this case the input real number 70 in the input field. Note that the following PID control loop parameters are real;

b. Gain KC: That is a proportionality constant, can be positive or negative. Set to 0.3 ;

c. Integral Time Ti: If you do not integral role in the integration time can be set to infinity Ti: 9999.99, the integration time in minutes, must be positive in this case is set to 30;

d. Derivative Time Td (Derivative Time): If no differential circuits, differential time Td can be set to zero. Differential time in minutes, must be positive in this case is set to 0 ;

e. Sample Time TS(Sample Time): is a PID control loop feedback sampling and re-calculate the time interval between the output values. The time in seconds, must be positive. This example is set to 0.1. Note: After the wizard is complete, if you need to modify this number, you must return to the wizard modified state cannot directly modify the table or in the program.

It needs to debug the PID parameters in actual operation.

View Data Block (DB), and Symbol Table (symbol table) corresponding content PID symbol label can be found in Table includes PID control loop with the core instruction, including the scale factor, integration time and so on. Copy this address table to the Status Chart (state table), the PID parameters can be modified online in monitor mode, without having to stop to do the configuration again. Commissioning appropriate parameters, the user can write in a data block, you can also do a wizard, or programming transmitted to the corresponding parameter data area [4]. In Data Block (data block), view parameters in PID command loop table. It is shown in Fig. 4:

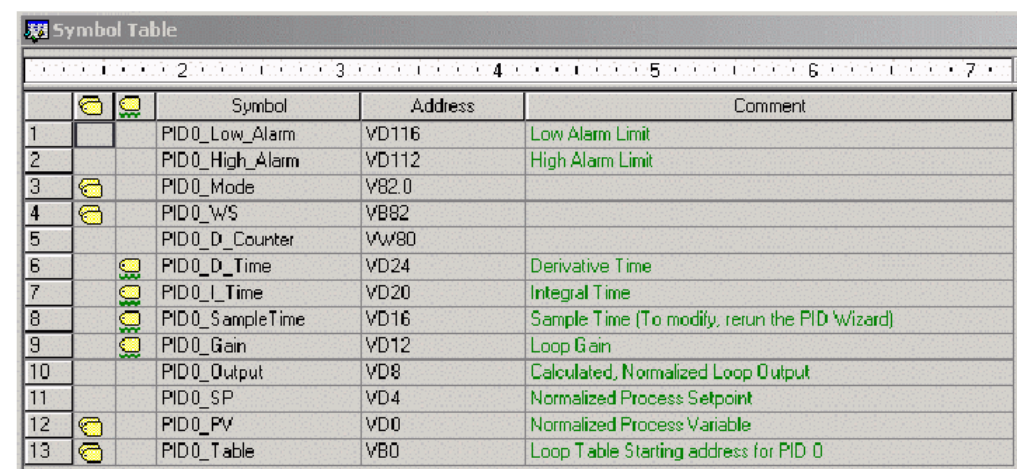

Figure. 4 Parameters in PID instruction loop sheet

After finishing PID wizard, it enters the corresponding parameters address in Status Chart (status table), then writes the online PID parameter values you need, so that the user can set PID parameters value and adjustments at any time according to the technological needs [11]. 
The control object is the pressure in PID control system, the feedback element of the measurement range is 0 - 16MPa. Signal feedback device after conversion to 0 - 20mA (or 4 $20 \mathrm{~mA}$ ) in the form of a current signal input to the analog input module EM235. Accordingly, we can set the range of feedback as Table 2 .

Table 2 Set the range of given and feedback

\begin{tabular}{|l|c|l|c|c|}
\hline & \multicolumn{2}{|c|}{ feedback } & set \\
\hline & $\begin{array}{l}\text { The actual } \\
\text { physical }\end{array}$ & Analog input values & Percentage & Unit \\
\hline High Range & $16 \mathrm{MPa}$ & 32000 & 100.0 & $\mathrm{~N} \times 16.0$ \\
\hline Low Range & $0 \mathrm{MPa}$ & $0(0-20 \mathrm{~mA})$ & 0.0 & 0.0 \\
\cline { 3 - 3 } & & $6400(4-20 \mathrm{~mA})$ & & \\
\hline
\end{tabular}

Note: For specific PID parameter values, each project is different, and requires on-site commissioning, there is no empirical parameter.

\section{Conclusion}

Using PLC and inverter to achieve energy saving in production lines PMS pneumatic control system, the practical application show that the control system is to save energy, improve the control performance, reduce throttling losses, reduce the original system noise and extend equipment life, reduce maintenance costs etc., improve production efficiency and economic benefits, has some promotional value.

\section{Acknowledgement}

This study is supported by Hubei Provincial Education Science "Twelfth Five Year Plan" 2014 Annual Project (project number: 2014B452); Hubei Province Humanities and Social Sciences project issues (project number: 14Y076).

\section{References}

[1] Zhang Guohua, Soviet Union and the principle of a typical production line, installation and commissioning of Beijing, Beijing Institute of Technology Press .2009: 11-12

[2] At the level converter and PLC control technology in the Water Supply System Inverter world .2011 August: 112-1113

[3] Wendell SRTake Control of PID Tuning [J] .Plant Engineer-ing, 2005.59 (9): 57-60

[4] With Plain PLC Application. Beijing Machinery Industry Press .2009: 126-129

[5] Siemens "S7-200 System Manual" PID instruction part of Siemens official website

[6] Junzhi Yu, Xiaolei Hu, Rui Ding, "Fuzzy Logic PID Based Control Design for Permanent Magnet Synchronous Motor Servo System", In Proceeding of 2009 Second International Conference on Intelligent Computation Technology and Automation, Vol. 2, pp.728 731, 2009.

[7] Liu Sheng, Xu Dong-hao, "Intelligent Control for Principal Axis of Variable Vector Propeller of Submersible Vehicle", In Proceeding of 2008 Eighth International Conference on Intelligent Systems Design and Applications, Vol. 2, pp.335 339, 2008.

[8] HaoBin Zhou, Bo Long, BingGang Cao, "Vector Control System of Induction Motor Based on Fuzzy Control Method", In Proceeding of 2008 Workshop on Power Electronics and Intelligent Transportation System, pp.136 139, 2008.

[9] Leehter Yao, Kian-Leong Lim, "Design of Adaptive Fuzzy PID Controller for Nonlinear System", In Proceeding of 2009 Fourth International Conference on Innovative Computing, Information and Control, pp.565 568, 2009.

[10] Jing Jiang, Shengping Wen, Zhiheng Zhou, Hezhi He, "Fuzzy Barrel Temperature PID Controller Based on Neural Network", In Proceeding of 2008 Congress on Image and Signal Processing, Vol. 1, pp.90 94, 2008. 
[11] Jun Hang, You-rui Huang, Li Li, "Switched Reluctance Motors Direct Torque Control Research Based on RBF Neural Network and Fuzzy Adaptive PID Controller", In Proceeding of 2010 Second International Conference on Intelligent Human-Machine Systems and Cybernetics, Vol. 1, pp.135 138, 2010. 